\title{
HUBUNGAN PEMILIHAN TEMPAT MEMBACA TERHADAP KEBETAHAN MEMBACA DAN KEMAMPUAN BERPIKIR MAHASISWA
}

\author{
Angela Christysonia Tampubolon ${ }^{1}$, Nisa Farasa ${ }^{2}$, Hanson E. Kusuma ${ }^{3}$ \\ Program Studi Magister Arsitektur, SAPPK, Institut Teknologi Bandung \\ Jl. B, Lb. Siliwangi, Kecamatan Coblong, Kota Bandung \\ *Email: ${ }^{1}$ angela.christysonia@gmail.com
}

\begin{abstract}
The selection of location is fathomed to influence different responses to students when reading. This study chose college students as respondents because reading is a daily learning process related to education or because of individual interests. College students choose a certain locations for reading and the relation between locations and respondents cause the responses to activity. Based on these, this study aimed to find the relation between the chosen reading locations and the students responses when doing reading activity. This study used quantitative research methods and online questionnaire as data collection instruments. To interpret the relations between reading locations and students reading responses, this study used explanatory quantitative research methods. Through open-ended question about the reason for selecting a certain location to read, was found that students reading responses are "Thinking Ability" and "Reading Attachment". College students choose some certain reading locations, but the majority of students tend to choose rooms and libraries. The results showed three reading clusters. In the first cluster "Campus and Public Spaces", was found that the ability to think and students reading attachment tended to be low. In the second cluster "Eating Area", was found that students tended to have the attachment of reading but still have difficulty to focus. While in the third cluster, "Home Environment" was found as the ideal reading environment because the ability to think and students reading attachment tended to be high.
\end{abstract}

Keywords: college students, reading attachment, the ability to think, reading space.

\section{PENDAHULUAN}

Masing-masing individu memiliki kebebasan dalam menemukan pengetahuan, salah satunya dengan membaca. Membaca merupakan salah satu bentuk belajar dan cara untuk memperoleh informasi. Dengan memberikan kebebasan, terutama dalam pemilihan bahan bacaan motivasi pelajar dalam membaca dapat ditingkatkan (Wigfield, 1994). Kegiatan membaca merupakan bagian dari pembelajaran yang biasa dilakukan sehari-hari oleh mahasiswa. Membaca biasa dilakukan atas dasar kebutuhan tertentu. Jika dikaitkan dengan alasan akademis, maka membaca menjadi kebutuhan dalam mengerjakan tugas atau mencari informasi. Membaca juga merupakan salah satu bentuk kegemaran. Kegiatan ini dapat terjadi dimana saja dan kapan saja. Ketika melakukan kegiatan pada sebuah ruang tertentu, maka akan timbul suatu respon terhadap lingkungan tersebut. Dalam penelitian ini, mahasiswa menjadi pelaku kegiatan membaca.

Terdapat beberapa lokasi yang dapat menjadi pilihan untuk melangsungkan kegiatan membaca. Beberapa lokasi diantaranya menyediakan fasilitas khusus berupa teknologi informasi (Harrop \& Turpin, 2013), ketersediaan buku, petugas yang siap membantu, listrik, dan perabotan (Jamieson, 2003) yang mendukung kenyamanan pengguna untuk membaca. Lokasi seperti ini dapat berupa perpustakaan atau kafe. Beberapa lokasi lainnya juga menawarkan suasana yang mendukung pengguna untuk membaca. Lingkungan terbuka hijau atau ruang yang familiar seperti di dalam rumah sendiri dapat menjadi lokasi pilihan. Setiap individu bebas memilih ruang membaca 
yang dianggap cenderung sesuai dan mendukung kegiatan yang akan dijalani. SavinBaden (2008) mengemukakan bahwa ruang belajar yang bersifat fleksibel dengan kebutuhan pengguna akan mendukung penggunanya dalam membangun pengetahuan tanpa ada paksaan. Penelitian ini ingin menemukan tempat membaca yang cenderung menjadi pilihan bagi para mahasiswa.

Selama melakukan kegiatan di lokasi tertentu, maka akan timbul respon yang dirasakan oleh pengguna. Penelitian Stone (2001) menemukan bahwa perasaan (mood) negatif seorang pelajar berasal dari tugas-tugas yang sedang ia kerjakan, sedangnya perasaan positif datang dari lingkungannya, khususnya pada lingkungan yang terbuka. Dapat disimpulkan bahwa kondisi fisik lingkungan dapat mempengaruhi manusia, salah satunya mempengaruhi secara afektif (Kinnafick \& Ntoumani, 2014). Pada penelitian ini, respon yang digunakan merupakan hasil eksplorasi respon yang berfokus pada kegiatan membaca sebagai bagian dari aktivitas belajar mahasiswa. Respon tersebut berupa kemampuan mahasiswa untuk berpikir selama melakukan kegiatan membaca dan kebetahan untuk membaca. Kemampuan berpikir disini merupakan kemampuan untuk berimajinasi dan fokus pada bacaan. Sedangkan kebetahan membaca merupakan bentuk respon untuk berlama-lama membaca dan munculnya perasaan ( $\mathrm{mood}$ ) ketika membaca.

Penelitian ini ingin menemukan tempat membaca yang cenderung dipilih oleh mahasiswa dan hubungannya dengan respon mahasiswa ketika membaca di tempat tersebut. Melalui hubungan tersebut, maka akan ditemukan kategori tempat yang dikelompokkan berdasarkan respon dalam melakukan kegiatan membaca. Pengelompokan tersebut dapat berdasarkan tinggi atau rendahnya kemampuan berpikir dan kebetahan mahasiswa selama membaca di tempat yang dipilih. Hasil yang diperoleh dalam penelitian ini dapat menjadi pertimbangan evaluasi fasilitas dan tempat yang diperuntukkan untuk fungsi membaca, khususnya dalam mendukung aktivitas akademik mahasiswa, baik di dalam perguruan tinggi maupun di luar lingkungan akademik.

\section{METODE PENELITIAN}

Penelitian ini menggunakan metode penelitian kuantitatif (Creswell, 2008) yang bersifat eksplanatori (Groat \& Wang, 2002). Penelitian kuantitatif eksplanatori bertujuan melihat bentuk hubungan antara tempat membaca terhadap respon mahasiswa dalam melakukan kegiatan membaca. Metode pengumpulan data menggunakan kuesioner online yang disusun secara kualitatif dan kuantitatif (mix-method). Pertanyaan kualitatif berupa pertanyaan terbuka (open-ended) mengenai nama tempat yang dipilih mahasiswa untuk melakukan kegiatan membaca. Pertanyaan kuantitatif berupa pertanyaan tertutup (close-ended) mengenai respon membaca.

Variabel respon membaca diperoleh dari hasil content analysis pertanyaan terbuka (openended) mengenai alasan penentuan tempat tertentu untuk membaca. Pertanyaan ini terlebih disebarkan terlebih dahulu pada tanggal 16 September 2015 dan berakhir pada 19 September 2015 kepada mahasiswa S1 dan S2 beberapa kota di Indonesia dengan total 75 orang dan memiliki variasi umur 17-35 tahun. Diperoleh 4 variabel respon membaca, yaitu "betah", "memicu mood", "bisa berimajinasi", dan "bisa fokus". Keempat variabel ini kemudian menjadi struktur pertanyaan tertutup (close-ended) dari kuesioner online.

Kuesioner online yang disusun secara kualitatif dan kuantitatif (mix-method) kemudian disebarkan secara bebas (snowball-non-randomsampling) melalui media sosial dan kenalan pribadi. Kuesioner online mulai disebarkan kembali pada tanggal 23 Oktober 2015 dan berakhir pada 31 Oktober 2015. Diperoleh responden sebanyak 116 orang dimana mahasiswa S1 sebanyak 95 orang dan mahasiswa S2 sebanyak 21 orang.

Mahasiswa diminta untuk menuliskan nama tempat yang dipilih untuk membaca melalui pertanyaan terbuka (open-ended). Mahasiswa kemudian diminta untuk mengukur tingkat respon ketika membaca di tempat yang dipilih melalui pertanyaan tertutup (closeended) yang disusun menggunakan metode semantic-differential (SD-method) berskala 1 sampai dengan 5 dengan kutub jawaban berupa kata sifat yang saling berlawanan. Bentuk pertanyaan di dalam kuesioner online (Tabel 1). 
Tabel 1. Bentuk pertanyaan pada kuesioner online

\begin{tabular}{|c|c|}
\hline $\begin{array}{l}\text { Kategori } \\
\text { Pertanyaan }\end{array}$ & Pertanyaan \\
\hline $\begin{array}{l}\text { Tempat } \\
\text { membaca }\end{array}$ & $\begin{array}{l}\text { Nama satu tempat/lokasi yang } \\
\text { paling sering anda gunakan untuk } \\
\text { membaca }\end{array}$ \\
\hline \multirow{8}{*}{$\begin{array}{l}\text { Respon } \\
\text { membaca }\end{array}$} & $\begin{array}{l}\text { Kemampuan anda untuk fokus } \\
\text { membaca di tempat tersebut. }\end{array}$ \\
\hline & $\begin{array}{llllllll}\begin{array}{l}\text { Sangat } \\
\text { tidak } \\
\text { fokus }\end{array} & 1 & 2 & 3 & 4 & 5 & \begin{array}{l}\text { Sangat } \\
\text { fokus }\end{array}\end{array}$ \\
\hline & $\begin{array}{l}\text { Kemampuan berimajinasi di tempat } \\
\text { membaca tersebut }\end{array}$ \\
\hline & $\begin{array}{lllllllll}\text { sangat } & & & & & & & & \text { sangat } \\
\text { tidak } & & & & & & \\
\text { mampu } \\
\text { mampu } & 1 & 2 & 3 & 4 & 5 & \text { berimaj } \\
\text { berimaji- } & & & & & & \text { inasi } \\
\text { nasi } & & & & & & \\
\end{array}$ \\
\hline & $\begin{array}{l}\text { Besarnya mood untuk membaca di } \\
\text { tempat membaca tersebut }\end{array}$ \\
\hline & $\begin{array}{lllllll}1 & 2 & 3 & 4 & 5 & \begin{array}{l}\text { Sangat } \\
\text { mood }\end{array}\end{array}$ \\
\hline & $\begin{array}{c}\text { Tingkat kebetahan di tempat } \\
\text { membaca tersebut }\end{array}$ \\
\hline & $\begin{array}{llllll}1 & 2 & 3 & 4 & 5 & \begin{array}{l}\text { Sangat } \\
\text { betah }\end{array}\end{array}$ \\
\hline
\end{tabular}

Data yang diperoleh dari pertanyaan terbuka (open-ended) berupa data teks yang bersifat kualitatif yang kemudian dianalisis menggunakan metode analisis kualitatif content analysis dan metode kuantitatif analisis distribusi. Content analysis bertujuan untuk mengetahui nama-nama tempat yang dipilih untuk membaca dan analisis distribusi digunakan untuk menemukan jumlah frekuensi dari jawaban yang paling sering muncul. Sedangkan data yang diperoleh dari pertanyaan tertutup (close-ended) berupa data numerik yang selanjutnya dianalisis menggunakan metode analisis komponen prinsip dan analisis faktor. Analisis komponen prinsip (principal component analysis atau PCA) bertujuan untuk menemukan komponen prinsip (variabel pengganti/variabel laten) yang dapat mewakili variabel terukur dengan cara mengumpulkan sebanyak mungkin variabilitas dari semua variabel terukur pada beberapa komponen prinsip yang utama.
Variabel laten respon membaca mahasiswa kemudian dihitung nilai rata-ratanya (mean) berdasarkan tempat membaca yang dipilih. Hasil mean ini selanjutnya dianalisis menggunakan analisis klaster yang bertujuan untuk mengelompokkan kategori berdasarkan kemiripan skor dari masing-masing kategori pertanyaan.

\section{HASIL DAN PEMBAHASAN}

Dari hasil content analysis menggunakan open coding untuk pertanyaan terbuka (openended) mengenai nama tempat yang cenderung digunakan untuk membaca, diperoleh 13 nama tempat. Hasil temuan ini kemudian menggunakan analisis distribusi untuk melihat frekuensi dari masing-masing jawaban yang (Gambar 1). Diperoleh bahwa mahasiswa cenderung memilih "Kamar" sebesar 53 $(45,68 \%)$ sebagai ruang yang paling banyak dipilih untuk melakukan kegiatan membaca. Mahasiswa juga cenderung memilih fasilitas umum "Perpustakaan" sebesar 22 (18,96\%) sebagai alternatif tempat membaca.

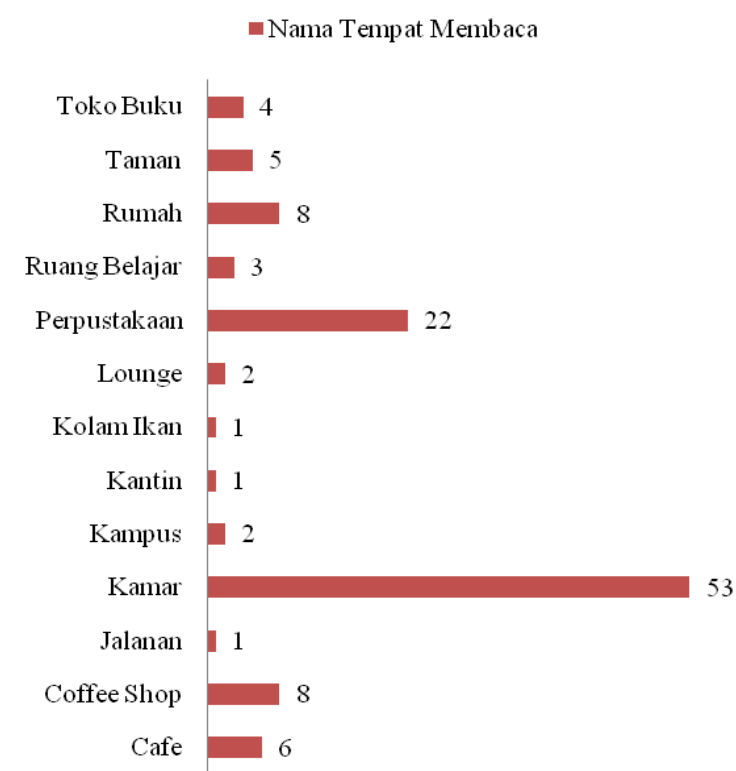

Gambar 1. Analisis distribusi data teks pertanyaan tempat yang sering digunakan untuk membaca

Dari hasil yang diperoleh, tiap-tiap lokasi memiliki kemiripan tipologi. Lounge, coffee shop, café, dan kantin merupakan area makan dan minum. Artinya, sebagian responden masih 
mempertimbangkan kesempatan untuk melakukan kegiatan lain selain membaca, seperti membeli makanan atau minuman, berkumpul dan bertemu dengan orang lain, dan memanfaatkan fasilitas tertentu yang dimiliki oleh tempat tersebut. Area ini juga merupakan area publik dan dapat diakses untuk umum. Untuk contoh lain, terdapat pula rumah, ruang belajar dan kamar yang memiliki sifat lebih privat dan tertutup untuk umum. Fasilitas di dalam ruang milik pribadi dianggap cukup memenuhi kebutuhan untuk membaca. Kampus dan perpustakaan merupakan fasilitas pendidikan yang sudah disediakan oleh perguruan tinggi. Tempat ini memberikan kesempatan untuk bertanya dan pilihan bacaan yang cenderung berguna untuk memenuhi kebutuhan akademik. Terdapat pula taman, jalanan, dan keberadaan kolam yang merupakan area terbuka. Hal ini membuka pemahaman bahwa membaca dapat dilakukan di banyak lokasi, baik bersifat publik atau privat, terbuka atau tertutup, memiliki fasilitas atau tidak, dan berada di lingkungan akademis, lingkungan tempat tinggal, ataupun di runag terbuka.

Data numerik yang diperoleh dari pertanyaan mengenai respon ketika membaca pada ruangan yang dipilih dianalisis menggunakan analisis komponen prinsip (principal component analysis atau PCA). Pada PCA, jumlah komponen prinsip (eigenvectors) ditentukan menggunakan Kaiser's (1960) stopping rule karena jumlah variabel pertanyaan kurang dari 30 (Steven, 1986 dalam Grimm \& Yarnold, 1960). Hasil PCA data respon mahasiswa diperlihatkan pada Tabel 2.

Tabel 2. Nilai eigenvalue analisis komponen prinsip respon afektif dalam membaca

\begin{tabular}{cccc}
\hline Num & Eigenvalue & Percent & Cum Percent \\
\hline 1 & 2.79 & 69.69 & 69.69 \\
2 & 0.55 & 13.73 & 83.42 \\
3 & 0.37 & 9.25 & 92.66 \\
4 & 0.29 & 7.34 & 100.00 \\
\hline
\end{tabular}

Dari Tabel 2, dan 3 tersebut dapat dilihat eigenvalue dari 4 komponen prinsip hasil analisis 4 variabel terukur. 2 komponen prinsip pertama memiliki eigenvalue lebih dari 1 (memiliki variabilitas melebihi variabel terukur, karena itu dapat digunakan untuk mewakili variabel terukur). 2 komponen prinsip (variabel laten) pertama memiliki cumulative percent $83.42 \%$, yang berarti bahwa 2 komponen prinsip pertama memiliki $83.42 \%$ porsi kemampuan yang dinilai cukup untuk menjelaskan dan mewakili fenomena dari 4 variabel terukur. Untuk memperoleh nama variabel, selanjutnya dilakukan analisis faktor dengan cara merotasi komponen prinsip dengan varimax rotation $=2$ secara ortogonal agar antar komponen tidak berkorelasi dan factor loading masing-masing variabel terukur terhadap faktor/variabel laten dibuat mendekati nol. Hasil temuan faktor/variabel laten hasil faktor analisis (Tabel $3)$.
Tabel 3. Faktor/Variabel Laten Hasil Faktor Analisis Dengan Varimax 2 Komponen Prinsip

\begin{tabular}{lll}
\hline \multicolumn{1}{c}{ Variabel } & $\begin{array}{c}\text { Kebetahan } \\
\text { membaca }\end{array}$ & $\begin{array}{c}\text { Kemampuan } \\
\text { berpikir }\end{array}$ \\
\hline Betah & 0.87 & 0.27 \\
Muncul mood & 0.81 & 0.36 \\
Bisa berimajinasi & 0.25 & 0.92 \\
Bisa fokus & 0.48 & 0.76 \\
\hline
\end{tabular}

'Kebetahan Membaca' yang menjelaskan respon tentang besarnya betah dan munculnya mood dalam membaca. Sedangkan variabel laten 'Kemampuan Berpikir' menjelaskan kemampuan mahasiswa untuk berimajinasi dan fokus sebagai wujud dari respon.

Hasil analisis faktor dari respon membaca mahasiswa selanjutnya diambil nilai rataratanya (mean) berdasarkan tempat membaca yang dipilih mahasiswa. Hasil mean respon membaca mahasiswa kemudian dianalisis menggunakan analisis klaster untuk diperoleh pengelompokan kategori berdasarkan kemiripan skor dari kategori tempat membaca. Analisis klaster dilakukan dengan menggunakan ward hierarchical clustering (Gambar 2). 


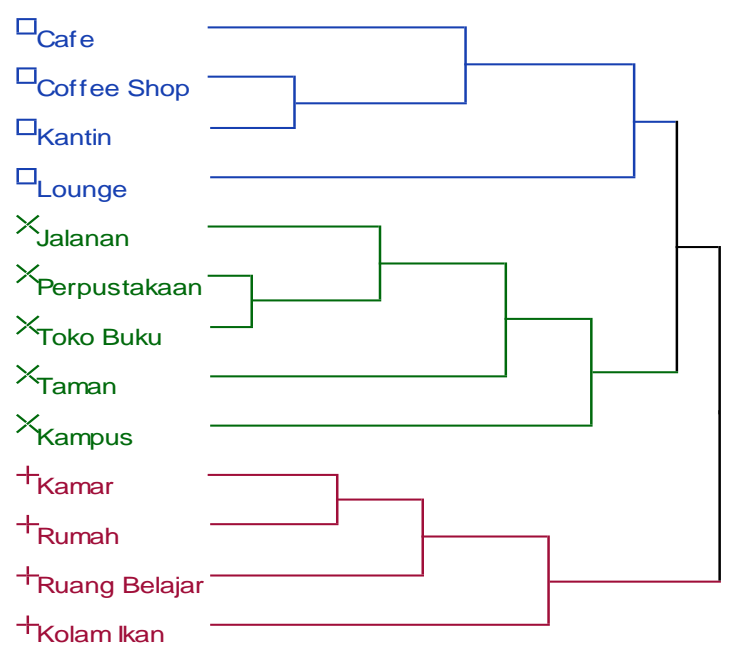

Gambar 2. Analisis Klaster Tempat Membaca Berdasarkan Respon Mahasiswa terhadap "Kemampuan Berpikir" dan "Kebetahan Membaca"

Ditemukan tiga bentuk klaster dari masing-masing tempat yang telah dipilih oleh mahasiswa. Seperti interpretasi di awal bahwa terdapat kemiripan tipologi tempat, maka hal yang sama juga ditemukan pada hasil analisa klaster tempat membaca. Pada klaster pertama, ditemukan kampus dan perpustakaan yang merupakan bentuk fasilitas dari lingkungan perguruan tinggi. Terdapat pula toko buku, taman, dan jalanan yang dapat dikategorikan sebagai area yang dapat diakses olleh publik. Berdasarkan lokasi dan bentuk fasilitasnya, klaster ini dikategorikan sebagai "Kampus dan Ruang Publik". Pada klaster kedua, terdapat café, coffee shop, kantin, dan lounge yang samasama memiliki ciri-ciri sebagai area makan dan berkumpul. Klaster ini dapat dikategorikan menjadi "Tempat Makan". Pada klaster ketiga, terdapat rumah, kamar, ruang belajar, dan kolam iklan yang dapat disimpulkan sebagai bagian dari lingkungan hunian dan bersifat privat. Klaster ini dapat dikategorikan sebagai "Lingkungan Rumah".

Hasil analisa klaster selanjutnya menggunakan scatter-plot untuk melihat persebaran nilai rata-rata (mean) dari masingmasing kategori tempat (Gambar 3).

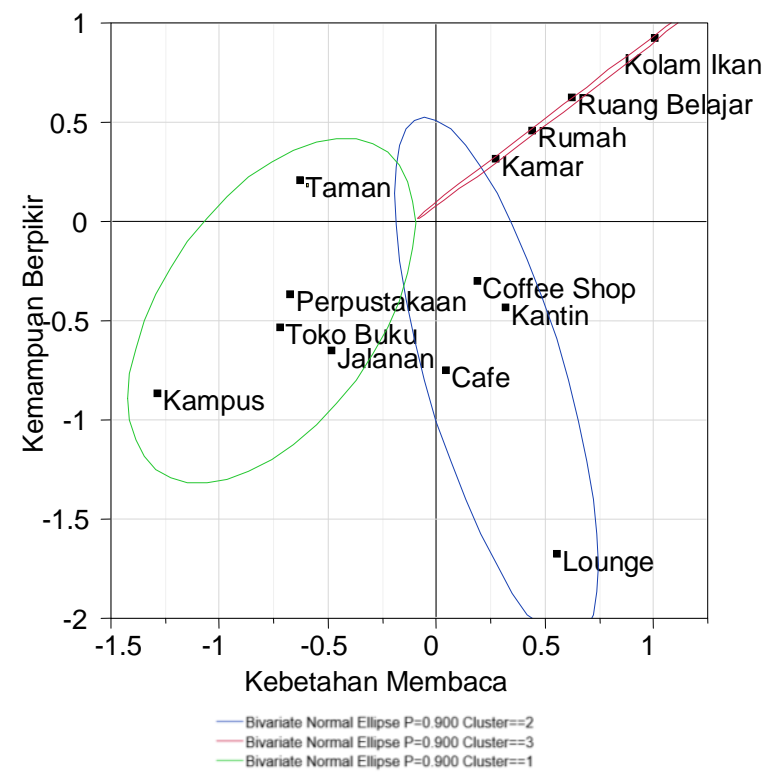

Gambar 3. Bivariate Fit of Mean (Kemampuan Berpikir) By Mean(Kebetahan Membaca)

Pada klaster pertama "Kampus dan Ruang Publik" $(\mathrm{p}=0.3834)$ ditemukan respon mahasiswa berupa kemampuan berpikir dan kebetahan membaca cenderung tidak rendah. Hasil ini menunjukkan bahwa fasilitas pendidikan pada perguruan tinggi belum tentu sesuai dengan penilaian dan kebutuhan mahasiswa untuk belajar, khususnya untuk melakukan kegiatan membaca. Namun hasil ini sebaiknya direplikasi kembali dengan tambahan variabel lain yang berkaitan dengan keberadaan fasilitas atau kelengkapan bahan bacaan yang sesuai dengan minat dan kebutuhan mahasiswa agar diperoleh hasil yang signifikan.

Pada klaster kedua "Tempat Makan" ( $p=$ 0.2935 ) ditemukan bahwa mahasiswa memiliki kebetahan yang cukup tinggi untuk melakukan kegiatan membaca di tempat tersebut. Namun, mahasiswa cenderung sulit untuk melakukan kegiatan yang membutuhkan fokus dan imajinasi. Hal ini cenderung disebabkan oleh keberadaan orang lain atau tingkat keramaian tempat tersebut. Mahasiswa cenderung betah karena klaster ini tidak hanya memberi ruang untuk membaca, namun juga memberi kesempatan untuk berkumpul dengan orang lain dan membeli makanan selama menggunakan tempat tersebut. Hasil ini sebaiknya direplikasi kembali dengan tambahan variabel yang berkaitan dengan keberadaan orang lain dan 
fasilitas pendukung kegiatan membaca agar hasil lebih signifikan.

Pada klaster ketiga "Lingkungan Rumah" $(\mathrm{p}=0.0006)$, ditemukan bahwa klaster ini merupakan tempat yang paling ideal untuk membaca karena respon kemampuan berpikir dan kebetahan membaca yang cukup tinggi. Lingkungan rumah merupakan area yang privat dan tidak mudah diakses oleh umum. Mahasiswa cenderung nyaman berada di lingkungan yang dikenal dan dapat menyesuaikan diri dengan lebih mudah jika ingin melakukan kegiatan membaca. Di dalam lingkungan rumah, mahasiswa dapat memilih ruangan yang sesuai. Seperti ruang belajar yang memang dibuat khusus sebagai area belajar, kamar untuk kegiatan membaca yang lebih santai, ataupun area dalam dan luar rumah yang dapat ditempati oleh diri sendiri atau bersama dengan orang lain.

\section{KESIMPULAN}

Nama tempat membaca yang dianalisis sehingga ditemukan 13 buah nama tempat yang cenderung digunakan oleh mahasiswa untuk membaca. Dari hasil analisis distribusi nama tempat membaca tersebut, ditemukan bahwa kamar dan perpustakaan merupakan tempat yang mayoritas dipilih untuk membaca. Jika melihat dari 13 nama tempat membaca tersebut, terdapat beberapa kemiripan tipologi. Beberapa mahasiswa cenderung memilih tempat membaca dengan kriteria yang privat dan tidak mudah diakses untuk umum, seperti rumah dan kamar. Terdapat beberapa mahasiswa yang cenderung melihat fasilitas yang ditawarkan, seperti adanya tempat menjual makanan dan minuman atau adanya fasilitas pendidikan yang menyediakan bacaan tertentu. Beberapa mahasiswa juga cenderung memilih area terbuka untuk membaca.

Dari hasil analisis mengenai respon membaca mahasiswa ditemukan dua variabel laten respon membaca, yaitu "Kemampuan Berpikir" dan "Kebetahan Membaca". Kemampuan berpikir berkaitan dengan kemampuan mahasiswa untuk fokus dan berimajinasi. Sedangkan kebetahan membaca berkaitan dengan kemauan mahasiswa untuk membaca lebih lama dan timbul perasaan senang selama membaca. Kedua respon ini kemudian dihitung nilai rata-ratanya (mean) berdasarkan lokasi yang dipilih untuk membaca.
Pada hasil analisis klaster tempat membaca berdasarkan respon mahasiswa terhadap "kemampuan berpikir" dan "kebetahan membaca", diperoleh 3 buah klaster tempat membaca. Pada klaster pertama "Kampus dan Ruang Publik", kemampuan berpikir dan kebetahan mahasiswa untuk membaca di kluster ini cenderung rendah. Pada klaster kedua "Tempat Makan" ditemukan bahwa mahasiswa cenderung betah membaca, namun kemampuan mahasiswa untuk berpikir cenderung rendah. Pada hasil kedua klaster ini perlu dilakukan replikasi ulang agar diperoleh hasil yang lebih signifikan. Hal ini cenderung disebabkan oleh jumlah jawaban dari tiap kategori tempat yang masih memiliki jumlah yang kecil. Namun hasil pengelompokan kategori pada penelitian ini cenderung memiliki kemiripan tipologi sehingga kesempatan untuk replikasi klaster yang lebih signifikan dapat dilakukan. Sedangkan pada klaster "Lingkungan Rumah" ditemukan bahwa kamar dan area tempat tinggal merupakan tempat yang paling ideal karena kemampuan berpikir dan kebetahan membaca mahasiswa cenderung tinggi dan memiliki hasil yang signifikan. Pada penelitian ini, mahasiswa dinilai cenderung memilih lingkungan tempat tinggal karena mahasiswa dapat menciptakan suasana dan kondisi yang sesuai dengan kebutuhan membaca dengan bebas, baik dengan ada atau tidaknya keberadaan orang lain.

Hasil temuan pada penelitian ini memiliki kelebihan karena berfokus pada salah satu kegiatan belajar mahasiswa, yaitu membaca. Hasil temuan variabel laten respon membaca mahasiswa juga merupakan hasil fokus pada kegiatan membaca. Kajian mengenai variabel laten respon membaca dapat menjadi pengetahuan tambahan untuk pembelajaran mengenai hubungan antara lingkungan pendidikan dengan pengguna, dalam hal ini mahasiswa. Hasil temuan ini dapat menjadi pertimbangan untuk akademisi dan tenaga pengajar dalam mengevaluasi lingkungan pendidikan yang mendukung kegiatan belajar mandiri mahasiswa.

\section{Daftar Pustaka}

Creswell, J. W., (2008) Research Design: Qualitative, Quantitative, and Mixed Methods Approaches. California: Sage Publications, Inc 
Grimm, L.G., \& Yarnold, P.R. (Eds.), (1995) Reading and understanding multivariate statistics. Washington, D.C.: American Psychological Association.

Groat, L. \& Wang, D., (2002) Architectural Research Methods. New York: John Wiley \& Sons. Inc.

Harrop, D \& Turpin, B., (2013) A study exploring learners' informal learning space behaviors, attitudes, and preferences. New Review of Academic Librarianship 19, no. 1, 58-77.

Jamieson, P., (2003) Designing more effective on-campus teaching and learning spaces: A role for academic developers. International Journal for Academic Development 8, no. 1-2, 119133.

Kaiser, H.F., (1960) The application of electronic computers to factor analysis. Educational and Psychological Measurement, 20, 141-151.

Ntoumani, C., (2014) The effect of the physical environment and levels of activity on affective states. Journal of Environmental Psychology 38, 241-251.

Savin-Baden, M., (2008) Learning spaces: Creating opportunities for knowledge creation in academic life. New York, NY: Society for Research into Higher Education \& Open University Press.

Stevens, J.P., (1986) Applied multivariate statistics for the social sciences. Hillsdale, NJ; Erlbaum.

Stone, N.J., (2001) Designing effective study. Environments. Journal of Environmental Psychology, 21, 179190.

Wigfield, A., (1994) Expectancy-value theory of achievement motivation: A developmental perspective. Educational Psychology Review, 6, 49-78. 